DOI: $10.17805 /$ zpu.2018.2.18

\title{
О шекспировском прообразе common man как героя современной драмы
}

\author{
Н. Э. МИКЕЛАДЗЕ
}

МОСКОВСКИЙ ГОСУДАРСТВЕННЫЙ УНИВЕРСИТЕТ ИМ. М. В. ЛОМОНОСОВА

В статье предпринята попытка выявления шекспировского прообраза для героя современной драмы обыкновенного человека (common man), как его обозначил американский драматург Артур Миллер в эссе «Трагедия и обыкновенный человек» (1949). Некоторые положения эссе были развиты в «Анатомии критики» (1957) Н. Фрая. Этой теоретической работой Миллер сопроводил свою пьесу «Смерть коммивояжера», обосновав претензии ее протагониста Вилли Ломена - маленького человека в жизненной иерархии - на статус трагедийного героя.

За 70 лет в англоязычной критике укоренилось сравнение этого героя с шекспировским Лиром. В нашей статье доказывается сущностная ошибочность такого сравнения и предлагается другая аналогия, также восходящая к трагедии «Король Лир»: Вилли - Глостер. Образ Глостера представляется нам прообразом, подлинным шекспировским архетипом common тап как героя современной драмы.

При этом драматический обыкновенный человек не является сегодня прямым продолжением Всякого человека (Everyman), который после «Улисса» Дж. Джойса все более тяготеет к эпической стихии.

Ключевые слова: У. Шекспир; Лир; Глостер; Артур Миллер; «Трагедия и обыкновенный человек»; “Смерть коммивояжера»; «Анатомия критики»; Нортроп Фрай; Улисс; Джеймс Джойс; драматургия

\section{ВВЕАЕНИЕ}

П роблема выявления шекспировского прообраза для обыкновенного человека (common man), героя современной драмы, встала передо мной довольно неожиданно. В 2015 г. на круглом столе, посвященном драматургии Артура Миллера (1915-2005), мне довелось вернуться к одной популярной шекспировской аналогии, нередко сопровождающей разборы пьесы «Смерть коммивояжера» (Death of a Salesman, 1949), и задаться вопросом: «В самом ли деле коммивояжер - это $\Lambda и р ? »$

Такая постановка проблемы оказалась далеко не бесплодной. Покажу логику рассуждения.

\section{АМЕРИКАНСКИЙ «КОРОАЬ АИР ?}

В англоязычной критике общим местом является уподобление Вилли Аомена, героя пьесы Миллера, шекспировскому Аиру: коммивояжер - $и$ р, копающийся в своем огороде-сердце. Эта аналогия родилась еще в театральных рецензиях на первую бродвейскую постановку пьесы зимой 1949 г. (театр Мороско, реж. Элиа Казан, в роли Вилли Аи Кобб). И если маститый Брукс Аткинсон осторожно описывал героя драмы Миллера как человека, чья прожитая «жизнь обернулась призраком... вдруг оказалась ничем» (Atkinson, 1949: 27), то критик газеты «Мэнчестер Гардиан» Ажерард

* Статья основана на докладе, сделанном автором на XLI Международной конференции Общества по изучению культуры США «Мир и разрешение конфликтов в американской культуре», 4-11 декабря 2015 г., МГУ имени М. В. Аомоносова, г. Москва.

The paper is based on the report made by the author at RSACS XLI International Conference "Imagining and Building Peace in American Culture", December 4-11, 2015, Lomonosov Moscow State University. 
Фэй спустя всего полгода с восторгом вспоминал нью-йоркский спектакль, «сравни-

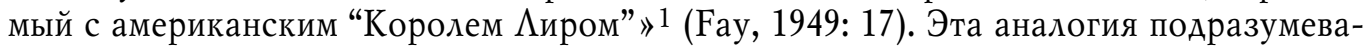
лась в әссе «Трагедия и обыкновенный человек» (Tragedy and the Common Man, 1949), которым драматург сопроводил пьесу ${ }^{2}$ : «Я верю, что обыкновенный человек (common man) является столь же подходящим героем для трагедии в самом высоком смысле, как были короли» (Miller, 1978: 3) 3 .

В 1950-х годах аналогия была закреплена авторитетом Мәри Маккарти. Признавая общность проблемы, она сопоставила Вилли (обобщенного Человека) и Аира (особенного индивида) как потенциальных героев газетной статьи, но так и не дала однозначного ответа на вопрос, кто из них более «универсален»: «Вилли - это... Человек с большой буквы, а не какой-то конкретный человек. Это тип, требующий статистического изучения и всеобщего безличного сочувствия, какое испытываешь при чтении редакционной статьи. Невозможно в передовице призвать внимание к случаю короля Аира. Хотя проблема та же: старый человек, уходящие силы, неблагодарные дети, и огромное желание “быть любимым" - точнее, получить доказательства любви, -

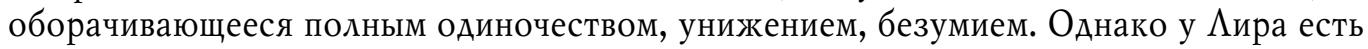
дар слова, человеческий, индивидуальный акцент, отличный от классовой окраски...

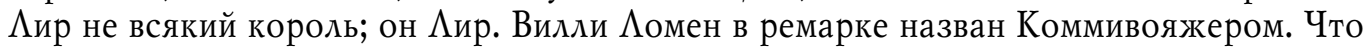
более универсально?» (McCarthy, 1956: xvi).

Впоследствии многие театральные критики, литературоведы и даже писатели прибегали к этому сравнению, опираясь на него или полемизируя с ним. Так, Аж. Кэрол Оутс спустя полвека признавала Вилли модельным американским трагическим героем, «нашим домашним Аиром» ${ }^{4}$ (Kolin, 1998: Электронный ресурс).

В статье «Вилли Аомен и король $\Lambda$ и» Пол Зигель исходил из того, что эти герои «разные, но проходят схожую катастрофу». Вилли (в котором, по мнению Зигеля, соединяются черты Шута и $и$ иа) «достигает величия и духа $\Lambda$ ира (grandeur and spirit of Lear). Оба героя обладают «громадной способностью мечтать и бороться». Наконец, обе трагедии вызывают в зрителе то, что необходимо для катарсиса, - «пафос, страх и жалость» (Siegel, 1956: 343-344).

Артуру Миллеру, очевидно, пришлось по душе это сравнение, и он не старался его разрушить. Ааже спустя 40 лет после первой постановки «Коммивояжера»в интервью Кристоферу Бигсби в 1990 г. он по-прежнему поддерживал эту параллель.

Проблему короля Аира Миллер видел в том, что в трагедии Шекспира «мрак до самого конца не рассеивался», страдание не облегчалось, и Аир уходил «неискупленным», не спасенным (unredeemed) (Arthur Miller and company, 1990: 56).

Если так прочитывать «Короля Аира», то, вероятно, «Смерть коммивояжера» действительно можно счесть его подобием. Однако такое прочтение существенно обедняет трагедию Шекспира и даже меняет ее смысл. Американский драматург, к сожалению, не разглядел у Шекспира главного - преображения героя. Не заметил и перышко в финале. Оно шевелится на губах Корделии:

Вы видите? Взгляните, губы, губы -

Взгляните же, взгляните...

(V, 3, 309-310. Пер. М. А. Кузмина; Шекспир, 1990: 323)

И следом сердце его разрывается. Как проницательно заметил еще Э. С. Брэдли в начале XX в., Аир умирает счастливьл, думая, что она жива (Bradley, 1912: 291)5. 
Весной юбилейного для Миллера 2015 г. (100-летие со дня рождения) Королевская шекспировская компания (RSC) впервые открыла свой новый сезон в Стратфорде-наЭйвоне не шекспировской пьесой. Театр поставил «Смерть коммивояжера» (реж. Грегори Аоран, в роли Вилли Энтони Шер).

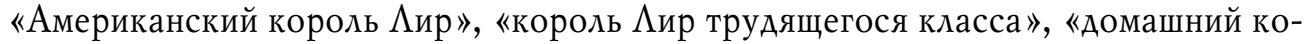
роль $\Lambda$ ир»... Пожалуй, не было ни одной рецензии, в которой не оживлялась бы (на том или ином основании 6 ) старая параллель. И художественный руководитель театра, постановщик спектакля Г. Аоран подтверждал:

"Аля меня "Смерть коммивояжера" - величайшая американская пьеса, уровня и силы шекспировских пьес. Миллер показал тему воплощенных и невоплощенных мечтаний так, как это делал Шекспир: сосредоточившись на частности (on the particular), которая каким-то чудом отражает всеобщее (create the universal)... Аумаю, правильно будет назвать Вилли, В известном смысле, домашним королем $\Lambda$ иром» ${ }^{7}$ (Belcher, 2015: Электронный ресурс).

Аоран, как видно, полемически развивает логику сопоставления М. Маккарти, не противопоставляя особое и всеобщее, а допуская универсальное в малом.

\section{ОБЩНОСТЬ В ТИПЕ КОНФАИКТА}

На мой взгляд, основания для такого сравнения если и есть, то коренятся они не в характере протагониста, а $b$ типе конфликта. В пьесе Миллера драматический конфликт состоит в столкновении между установленным порядком и взрывающей его истиной. Следовательно, он восходит к основному конфликту всей мировой драмы: столкновению между иллюзиями и действительностью, между слепотой и зрячестью. Так его понимали еще в глубокой древности, буквально раскрывая миф о зрячем незнающем Эдипе и слепом мудреце Тиресии. Подобный конфликт всегда реализуется в форме узнавания (анагноризис Аристотеля), т. е. в переходе от незнания к знанию, метафорически от действительной слепоты к подлинной зрячести.

Так и у Миллера. Араматический конфликт в его пьесах тоже, как правило, реализуется в форме узнавания, самосознания.

Правда, к которой человек приходит в процессе самоосознания, сталкивается с существующим $b$ мире порядком и одновременно с теми установками $b$ самом человеке, которые говорят о его социальных обязательствах. В результате этого столкновения у героя (маленького человека - low man) возникает чувство социального страха. Coциальный страх - это страх обыкновенного человека, вступившего в схватку с миром, социумом, с чем-то неизмеримо большим, чем он, и бесчеловечным. Примерно так понимал конфликт своих драм сам Артур Миллер. Он писал об этом в эссе «Трагедия и обыкновенный человек» (1949) и позднее возвращался к этим вопросам в эссе «О социальных пьесах» (On Social Plays, 1955) и интервью (Centola, 1984: 348).

В итоге мы получаем все тот же базовый конфликт между иллюзиями и действительностью, перенесенный в сознание человека. Этот конфликт вечен, потому что идеального решения не имеет. Эдипов конфликт, конфликт $\Lambda$ ира и Глостера. Что лучше? Знать и принять на себя ответственность? Или оставаться в счастливом неведении?

В американской критике (а вслед за ней и в отечественной) укоренилось это сравнение: Вилли - Аир. Прежде к нему прибегала и я, рассуждая о герое и жанровой принадлежности драмы Миллера (Микеладзе, 1991). Впрочем, уже на том этапе у меня не получалось признать «Смерть коммивояжера» трагедией (тогда как сам Миллер 
настаивал на трагедийности своего героя). Вместе с тем ее можно определить как патетическую трагедию, если следовать классификации Нортропа Фрая, который отнес современную мелодраму к разряду «низкой миметической трагедии», для которой больше подходит понятие «пафос», тесно связанное с эмоциональностью (Фрай, 1987: 237-238).

И только недавно я поняла, что такое соотнесение все же не бесплодно, и у героя Миллера в великой шекспировской трагедии, пожалуй, действительно есть аналог. Но это не $\Lambda$ ир, а Глостер.

\section{ГАОСТЕР - ПРЕАТЕЧА «ОБЫКНОВЕННОГО ЧЕАОВЕКА»}

Аиния Глостера и сыновей... Параллельный сюжет, который развернут драматургом от начала до конца. Уникальный случай в его трагедиях! Ао сих пор многие задаются вопросом, зачем это было сделано. Чтобы показать не единичность подобных историй в жизни? Аа, наверное. Но не только. Этого требовал принцип полноть, свойственный средневековому сознанию: картину насилия над духом (линию Аира) нужно было дополнить и оттенить изображением насилия над телом, плотью (линией Глостера). Антитезу тела и духа впервые отметил в своем предисловии к «Королю ру» Харли Гренвилл-Баркер (1927).

В самом деле, Аир у Шекспира - не только отец и король, он человек, в котором свернуты огромные духовные ресурсы. Пройдя через безумие, через драму отчаянного прозрения, он открывает Божественную мудрость, которая заключается в жалос-

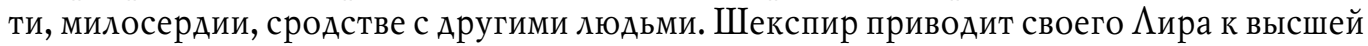
степени милости (caritas) и сострадания:

Никто не виноват, никто!

(IV, 6, 166. Пер. М. Кузмина; Шекспир, 1990: 288).

Араматический и духовный путь шекспировского Аира лежит через отказ от эгоизма, через покорение стихиям природы, к полной утрате себя прежнего и преображению через мудрое безумие: «Если кто из вас думает быть мудрым в веке сем, тот будь безумным, чтобы быть мудрым. Ибо мудрость мира сего есть безумие перед Богом...» (1Кор 3: 18-19).

В таком узнавании заключена победа, даже если герой гибнет в финале. Аир прошел труднейшее из всех испытание милосердием. Распятый на «дыбе этого мира» ("upon the rack of this tough world" V, 3, 313; Shakespeare, 1990: 205), он обрел прозрение-узнавание и постиг истинную мудрость «перед Богом»: "None does offend, none, I say, none; I'll able' them: Take that of me..." IV, 6, 166-167; Shakespeare, 1990: 169).

Этого измерения, да и вообще этой темы нет в пьесе Миллера. И Шута, который научил бы протагониста мудрому безумию, здесь тоже нет. Нет, впрочем, и Эдгара, который учил своего отца Глостера христианскому смирению и уберег от самоубийства ${ }^{8}$. Ни брат Вилли Бен, ни его сын Биф не годятся на эти роли и не спасают его.

И все же если Вилли с кем-либо и можно сравнить в этой великой трагедии, то именно с Глостером, который, потеряв глаза, начинает прозревать, но не справляется с узнаванием, не может вынести тяжкое бремя знания.

Глостер в трагедии Шекспира ближе всех к обькновенному человеку: он сладострастник («причастен»к рождению бастарда), он легковерен, тщеславен, вспыльчив. Точно таков и Вилли Аомен. 
Глостеру с самого начала свойственно непонимание себя.

Но ослепленный, он, наконец, ясно увидел себя таким, каков есть, а в мире открыл нравственный хаос. И это стало для него худшим наказанием. После встречи с безумным Ииром он говорит:

Король безумен, а мой жалкий разум

При мне остался, чтобы ощущал я

Безмерность горя. Аучше б помешаться;

Тогда бы мысли отвлеклись от скорби

И боль казалась выдуманной только,

Себя не сознавая.

(IV, 6, 276-281. Пер. М. Кузмина; Шекспир, 1990: 294).

«Единственная вещь, которую заурядный плотский человек... не может стерпеть, - это правда. Аучше смерть или безумие!» - писал Гренвилл-Баркер (GranvilleBarker, 1972: 317). И это герой Шекспира... Он не титан, конечно, не Иир. Он и сам знает свою слабость и нестойкость:

...Не дайте скверной мысли (my worser spirit) вновь склонить

К досрочной смерти!

(IV, 6, 215-216. Пер. М. Кузмина; Шекспир, 1990: 291).

Глостер - это уже образ обыкновенного человека, который и становится в XX в. героем современной низкой миметической трагедии. Именно Глостер - прообраз Вилли Иомена, модельного героя (common man) современной драмы.

Не всякому человеку посильно вынести правду. Герои Миллера слабы, они маленькие, плотские, зависимые от материального начала люди перед большим черствым каменным истуканом - обществом. Между тем, если человек хочет ясно видеть мир, он должен освободиться от тирании плоти, от материального. Именно этому учил безумный $\Lambda$ ир слепого Глостера в своем самом пронзительном монологе: «Чудак! Чтобы видеть ход вещей на свете, не надо глаз. Смотри ушами. Видишь, как судья издевается над жалким воришкой? Сейчас я покажу тебе фокус. Я все перемешаю. Раз, два, три! Угадай теперь, где вор, где судья. Видел ты, как цепной пес лает на нищего? <...> А бродяга от него удирает. Заметь, это символ власти. Она требует повиновения. Пес этот изображает должностное лицо на служебном посту.

Ты уличную женщину плетьми

Зачем сечешь, подлец, заплечный мастер?

Ты б лучше сам хлестал себя кнутом

За то, что согрешить с ней хочешь втайне.

Мошенника повесил ростовщик.

Сквозь рубища грешок ничтожный виден,

Но бархат мантий прикрывает все.

Позолоти порок - о позолоту

Судья копье сломает, но одень его

В лохмотья - камышом проколешь...

(IV, 6, 148-165. Пер. Б. А. Пастернака; Шекспир, 1960: 536-537).

Маленький человек Вилли не способен так освободиться. 
О ТРАГИЧЕСКОЙ ПОБЕАЕ

В эссе «Трагедия и обыкновенный человек» А. Миллер писал: «...Трагическое чувство возникает в нас в присутствии героя, который готов, если необходимо, пожертвовать свою жизнь ради сохранения одного - чувства собственного достоинства» (Miller, 1978: 3-4).

Вероятно, так драматург понимал самоубийство Иомена: «жертва» ради сохранения чувства собственного достоинства.

В сопровождающем пьесу эссе Миллер и сам говорит о «возможности победы», которая «должна быть в трагедии». Однако в рассуждении драматурга содержится неустранимое противоречие. Если «победа» трагедии заключена в «оптимистической вере в совершенство человека» (там же: 7), то может ди самоубийство - т. е. неспособность вынести реальность - быть доказательством и проявлением такой веры?

В драме Миллера нет в финале главного, что позволило бы назвать ее трагедией, nобеды протагониста: Вилли умирает, стремясь отстоять свое человеческое достоинство, но руководят им все те же ложные мечты и пустые надежды, от которых он был не в силах отказаться.

В сцене самоубийства мысли этого одинокого, испуганного, заблудившегося в жизни человека все о том же: «Можешь себе представить, какое будет счастье (magnificence), когда у мальчика в кармане окажется двадцать тысяч долларов? ...Это очень сильный, ловкий ход (very smart), понимаешь?.. Представляешь себе? Когда он получит страховку, он опять переплюнет (he'll be ahead of) Бернарда... Великолепная сделка во всех отношениях! (A perfect proposition all around) ...Я всегда знал, что так или иначе, но мы с Бифом своего добьемся! ...Бей сильно и низко, ведь это так важно, мальчик (it's important)! На трибунах сидят важнысе люди (important people), не успеешь ты оглянуться...» (Миллер, 1999: 269; Miller, 1998: 108; курсив в цитатах мой. - H. М.).

И с этим багажом - заботой о материальном гораздо более, чем о духовном, он уходит в смерть. Мифологема пути человеческой жизни, изначально связанная с древним комплексом смерти как нового рождения (которое и есть условие будущей победы), предстает в истории Вилли, скорее, в пессимистическом варианте.

Так трогательный common man Вилли Иомен оказывался не способен вынести правду и жизнь и до самого конца оставался погруженным в мечту о материальном. В то время как трагический $\Lambda$ ир, вынесший больше всех (“hath born most” V, 3, 324; Shakespeare, 1990: 206), возрастал в духе.

\section{ЗАКАЮЧЕНИЕ}

Спустя десятилетие после «Смерти коммивояжера» драматург по-прежнему видел главное препятствие в создании современной трагедии не в своем герое, а в обществе: в невозможности для общества признать кого-либо уполномоченным задать основной вопрос: «Мы настолько атомизированы, что ни один персонаж в пьесе не может с убедительностью взять на себя роль нашего героического “вопрошающего”... В тот момент, когда любой человек драматически охарактеризован и выведен как трагический герой, наш здравый смысл низводит его до уровня жалобщика, отверженного» (Miller, 1957: 9-10).

Н. Фрай в «Анатомии критики» (1957) полемически развил эту мысль Миллера, рассматривая в качестве героя современного низко миметического модуса ${ }^{9}$ «козла отпущения», «типичную или случайную жертву» (Фрай, 1987: 240), вызывающую у нас сочувствие своей «слабостью и одиночеством» (там же: 237). 
Наконец, исследование приводит нас к еще одному важному умозаключению: объкновенный человек (common man) как концепт не есть прямое продолжение Всякого человека (Everyman). Всякий человек универсален: соединяет душу и плоть, небо и землю. Он всегда в значительной степени фигура, а не сосед по дому. Всякий и Никто... Поиски Ажеймсом Ажойсом архетипа такого универсального, всеобъемлющего героя для нашего времени увенчались в начале XX в. фигурой Улисса.

Ажойс искал наиболее «законченный, всесторонний характер» (complete all-round character), представленный в мировой литературе. Христос? Нет, «он был ученым и никогда не жил с женщиной», а это «одна из самых трудных вещей». Он отвергает Фауста - «человек без возраста, дома и семьи», вокруг него вечно вьется Мефистофель, значит, в нем нет завершенности. Гамлет - конечно, Человек (a human being), «но он только сын». Улисс - это и сын... и отец... и муж... и любовник... и воин... и царь... и изобретатель. ...Я вижу его со всех сторон... как скульптурную фигуру. Но завершенность его и в том, что он добрый малый (“а good man”). ...Он не бог, ему свойственны все изъяны обычного человека, но он хороший человек» (Ellman, 1982: 435-436).

Улисс и сегодня остается, вероятно, лучшим прообразом Всякого человека, архетипом для нового всестороннего, эпического по преимуществу, героя. Тогда как прообразом объкновенного человека, героя современной драмы, не справляющегося с узнаванием, является шекспировский Глостер.

Прошу считать эти заметки постановкой проблемь, которая заслуживает дальнейшей разработки и чревата масштабными выводами и обобщениями.

\section{ПРИМЕЧАНИЯ}

1 Аондонская постановка, осуществленная летом того же года, напротив, вызвала по большей части разочарование.

2 Работа была впервые опубликована в газете «Нью-Йорк таймс» 27 февраля 1949 г.

3 Энох Брейтер, комментируя эссе Миллера, справедливо отмечал, что Вилли Аомен был «разработан» как герой, способный достичь уровня трагических фигур «масштаба Эдипа и $\Lambda$ pa» (Brater, 2010: xxxviii).

4 "Our quintessential American tragic hero, our domestic Lear". В той же дискуссии Ажоан Шенкар назвала «Смерть коммивояжера» единственной полноценной американской трагедией

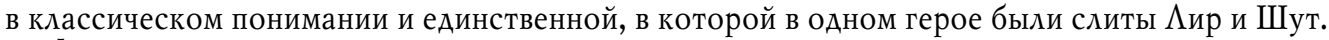

5 В предсмертных словах $и$ ира Эндрю Сесил Брэдли предлагал видеть "an unbearable joy" и ожидал соответствующего исполнения этой сцены от актеров (Bradley, 1912: 291).

6 Майкл Биллингтон увидел общность Вилли и Аира в том, что оба они - люди, «плохо владеющие собой» ("he hath ever but slenderly known himself" I, 1, 292-293; Shakespeare, 1990: 21).

7 "I believe 'Death of a Salesman' is the greatest American play and is of a scale, ambition and power of any Shakespeare play", "Miller has created the burden of fulfilling or not fulfilling dreams in the way that Shakespeare did... I think it's correct to say Willy is a domestic King Lear in a way".

Счастлив ты, отец.

Благодари богов. Себе во славу,

Ааря нам чудеса, тебя спасли.

$$
\text { Глостер }
$$

Запомню. И сносить я горе буду,

Пока само не крикнет мне: «Аовольно!»

Тогда умру.

(IV, 6, 72-77. Пер. М. Кузмина; Шекспир, 1990: 284). 
9 Фрай относит к низкому мимесису драму, основанную на пафосе (Фрай, 1987: 237-238), ироническую комедию (там же: 238-239), детектив и мелодраму (там же: 244-245).

\section{СПИСОК АИТЕРАТУРЫ}

Миллер, А. (1999) Смерть коммивояжера // Миллер, А. Пьесы / пер. Е. Голышевой и Б. Изакова. М. : Гудьял-пресс. 608 с. С. 125-274.

Микеладзе, Н. Э. (1991) Театр Артура Миллера: конфликт, герой, жанр : дис. ... А-ра филол. наук. М. 252 с.

Шекспир, У. (1960) Король Аир // Шекспир, У. Полное собрание сочинений / пер. Б. А. Пастернака : в 8 т. М. : Искусство. Т. 6.687 с. С. 427-568.

Шекспир, У. (1990) Пьесы в переводе Михаила Кузмина. М. : Московский рабочий. 432 с.

Фрай, Н. (1987) Анатомия критики // Зарубежная эстетика и теория литературы XIX-XX вв. Трактаты, статьи, эссе. М. : Изд-во МГУ. 512 с. С. 232-263.

Arthur Miller and company (1990): Arthur Miller talks about his work in the company of actors, designers, directors, reviewers and writers. Ed. C. W. E. Bigsby. Methuen Drama in association with the Arthur Miller Centre for American Studies. 240 p.

Atkinson, B. (1949) At the Theatre// The New York Times, 11 Feb. P. 27.

Belcher, D. (2015) "Death of a Salesman" opens new season for Royal Shakespeare Company // The New York Times, 31 March. URL: https://www.nytimes.com/2015/04/01/arts/international/ death-of-a-salesman-opens-new-season-for-royal-shakespeare-company.html (дата обращения: 12.01.2018).

Billington, M. (2015) Death of a Salesman five-star review - Antony Sher is extraordinary // The Guardian, 2 Apr. URL: https://www.theguardian.com/stage/2015/apr/02/death-of-a-salesman-review-antony-sher-harriet-walter-arthur-miller-rsc (дата обращения: 12.01.2018).

Bradley, A. C. (1912) Shakespearean Tragedy. Lectures on Hamlet, Othello, King Lear, Macbeth. 2 ed. Macmillan \& Co, St. Martin's Street, London. 522 p.

Brater, E. (2010) Commentary // Miller, A. Death of a Salesman. With commentary and notes by Enoch Brater. London, Methuen Drama. lv; 131 p.

Centola, S. R. (1984) The Will to Live: An Interview with Arthur Miller // Modern Drama. Vol. 27, № 3. P. 345-360.

Ellman, R. (1982) James Joyce. New and revised edition. Oxford University Press. 961 p.

Fay, G. (1949) Death of a Salesman // The Manchester Guardian, 30 Jul. P. 17.

Granville-Barker, H. (1972) King Lear // Granville-Barker, H. Prefaces to Shakespeare, in 2 vol. Batsford, London. Vol. 1, 449 p. P. 261-334.

Kolin, Ph. (1998) Death of a Salesman: A Playwrights' Forum / Michigan Quarterly Review. Vol. 37, issue 4. URL: https://quod.lib.umich.edu/cgi/t/text/text-idx?cc=mqr;c $=$ mqr; $c=$ mqrarchive; $\mathrm{idno}=$ act2080.0037.402;view=text;rgn=main;xc=1;g=mqrg (дата обращения: 12.01.2018).

McCarthy, M. (1956) Introduction // Sights and Spectacles, 1937-1956. N. Y., Farrar, Straus \& Cudahy. xvi, $183 \mathrm{p}$.

Miller, A. (1957) On Social Plays // Miller, A. A View from the Bridge. London, Cresset. P. 1-18.

Miller, A. (1978) Tragedy and the Common Man // The Theater Essays of Arthur Miller. Ed. with an introduction by Robert A. Martin. New York, Viking Press, xliv; 401 p. P. 3-7.

Miller, A. (1998) Death of a Salesman. Certain Private Conversations in Two Acts and Requiem. With an introduction by Christopher Bigsby. Penguin Books. xxvii; 113 p. $246 \mathrm{p}$.

Shakespeare, W. (1990) King Lear. Ed. by K. Muir. The Arden Shakespeare. Routledge. lviii;

Siegel, P. N. (1956) Willy Lomen and King Lear // College English, vol. 17, №6. P. 341-345.

Aата поступления: 12.02.2018 2. 


\section{THE SHAKESPEAREAN PROTOTYPE OF THE COMMON MAN \\ AS THE HERO OF MODERN DRAMA \\ N. E. MIKELADZE \\ LOMONOSOV MOSCOW STATE UNIVERSITY}

In the article an attempt is made to reveal the Shakespearean prototype for the hero of modern drama - the common man - as he was marked by the American playwright Arthur Miller in the essay "Tragedy and the Common Man" (1949). Some statements of the essay were developed in N. Frye's "Anatomy of Criticism" (1957). With this theoretical work Miller accompanied his play "Death of a Salesman", substantiating the claims of its protagonist Willy Loman, a low man in the life hierarchy, to the status of a tragic hero.

For seventy years, the comparison of this hero with Shakespeare's Lear took root in Englishspeaking criticism. In this paper, the essential error of such a comparison is proved, and another analogy is proposed, which also goes back to the tragedy "King Lear": Willy - Gloucester. The image of Gloucester appears to us as a prototype, a genuine Shakespearean archetype of the common man as the hero of modern drama.

At the same time, the dramatic common man today is not a direct continuation of Everyman, which tends increasingly towards the epic element, especially after "Ulysses" by J. Joyce.

Keywords: W. Shakespeare; Lear; Gloucester; Arthur Miller; "Tragedy and the Common Man"; "Death of a Salesman"; “Anatomy of Criticism”; Northrop Frye; Ulysses; James Joyce; drama

\section{REFERENCES}

Miller, A. (1999) Smert' kommivoiazhera. In: Miller, A. P'esy / Transl. by E. Golysheva and B. Izakov. Moscow, Gud'ial-press. 608 p. Pp. 125-274. (In Russ.).

Mikeladze, N. E. (1991) Teatr Artura Millera: konflikt, geroi, zhanr: Dis.... Doctor of Philology. Moscow. 252 p. (In Russ.).

Shekspir, U. (1960) Korol' Lir. In: Shekspir, U. Polnoe cobranie cocbinenii / transl. by B. L. Pasternak : in 8 vol. Moscow, Iskusstvo. Vol. 6. 687 p. Pp. 427-568. (In Russ.).

Shekspir, U. (1990) P'esy v perevode Mikbaila Kuzmina. Moscow, Moskovskii rabochii. 432 p. (In Russ.).

Frai, N. (1987) Anatomiia kritiki // Zarubezbnaia estetika i teoriia literatury XIX-XX vv. Traktaty, stat' $i$, esse. Moscow, Izd-vo MGU. 512 p. Pp. 232-263. (In Russ.).

Arthur Miller and company (1990): Arthur Miller talks about bis work in the company of actors, designers, directors, reviewers and writers. Ed. C. W. E. Bigsby. Methuen Drama in association with the Arthur Miller Centre for American Studies. 240 p.

Atkinson, B. (1949) At the Theatre. The New York Times, 11 Feb., p. 27.

Belcher, D. (2015) "Death of a Salesman" opens new season for Royal Shakespeare Company. The New York Times, 31 March [online] Available at: https://www.nytimes.com/2015/04/01/arts/international/death-of-a-salesman-opens-new-season-for-royal-shakespeare-company.html (access date: 12.01.2018).

Billington, M. (2015) Death of a Salesman five-star review - Antony Sher is extraordinary. The Guardian, 2 Apr. [online] Available at: https://www.theguardian.com/stage/2015/apr/02/death-ofa-salesman-review-antony-sher-harriet-walter-arthur-miller-rsc (access date: 12.01.2018).

Bradley, A. C. (1912) Shakespearean Tragedy. Lectures on Hamlet, Otbello, King Lear, Macbeth. 2 ed. Macmillan \& Co, St. Martin's Street, London. 522 p.

Brater, E. (2010) Commentary. In: Miller, A. Death of a Salesman. With commentary and notes by Enoch Brater. London, Methuen Drama. lv; 131 p.

Centola, S. R. (1984) The Will to Live: An Interview with Arthur Miller. Modern Drama, vol. 27, no. 3, pp. 345-360.

Ellman, R. (1982) James Joyce. New and revised edition. Oxford University Press. 961 p.

Fay, G. (1949) Death of a Salesman. The Manchester Guardian, 30 Jul., p. 17.

Granville-Barker, H. (1972) King Lear. In: Granville-Barker, H. Prefaces to Shakespeare : in 2 vol. Batsford, London. Vol. 1, 449 p. P. 261-334. 
Kolin, Ph. (1998) Death of a Salesman: A Playwrights' Forum. Michigan Quarterly Review, vol. 37, issue 4 [online] Available at: https://quod.lib.umich.edu/cgi/t/text/text-idx?cc= mqr $; c=$ mqr $; c=$ mqrarchive;idno $=$ act2080.0037.402; $\mathrm{view}=$ text; $; \mathrm{rgn}=$ main; $\mathrm{xc}=1 ; \mathrm{g}=$ mqrg (access date: 12.01.2018).

McCarthy, M. (1956) Introduction. In: Sights and Spectacles, 1937-1956. N. Y., Farrar, Straus \& Cudahy. xvi, 183 p.

Miller, A. (1957) On Social Plays. In: Miller, A. A View from the Bridge. London, Cresset. P. 1-18.

Miller, A. (1978) Tragedy and the Common Man. In: The Theater Essays of Artbur Miller. Ed. with an introduction by Robert A. Martin. New York, Viking Press, xliv; 401 p. P. 3-7.

Miller, A. (1998) Death of a Salesman. Certain Private Conversations in Two Acts and Requiem. With an introduction by Christopher Bigsby. Penguin Books. xxvii; 113 p. $246 \mathrm{p}$.

Shakespeare, W. (1990) King Lear. Ed. by K. Muir. The Arden Shakespeare. Routledge. lviii;

Siegel, P. N. (1956) Willy Lomen and King Lear. College English, vol. 17, no. 6, pp. 341-345.

Submission date: 12.02 .2018$.

Микеладзе Наталья Эдуардовна - доктор филологических наук, профессор кафедры зарубежной журналистики и литературы Московского государственного университета им. М. В. Аомоносова. Адрес: 125009, Россия, г. Москва, ул. Моховая, А. 9. Тел.: +7 (495) 629-74-35. Эл. адpec: fornatalia@bk.ru

Mikeladze Natalya Eduardovna, Doctor of Philology, Professor, Department of Foreign Journalism and Literature, Lomonosov Moscow State University. Postal address: 9, Mokhovaya St., Moscow, Russian Federation, 125009. Tel.: +7 (495) 629-37-80. E-mail: fornatalia@bk.ru 